\section{'Toy' laser macular burns in children}

N Raoof ${ }^{1,2}$, TKJ Chan ${ }^{1,2}$, NK Rogers ${ }^{1,2}$, W Abdullah², I Haq ${ }^{1}$, SP Kelly ${ }^{3}$ and FM Quhill ${ }^{1}$

consumers about the risk of eye and skin injuries from exposure to high-powered laser pointers. FDA regulations limit the energy output of hand-held laser pointers to 5 milliwatts $(\mathrm{mW}) .{ }^{1}$ However, laser 'toys', of uncertain safety classification and which resemble low-power laser pointers, can be purchased online from outside Europe and USA. Such lasers have the potential for retinal damage. Importantly as laser technology continues to develop, more powerful portable (hand-held) lasers are being produced at lower cost. We report five local children with maculopathy following exposure to laser toys purchased online and imported to the UK.

\section{Case reports}

\section{Case 1}

A nine-year-old boy, with a history of right amblyopia, presented on Boxing Day with a $24 \mathrm{~h}$ history of painless vision loss in his better eye. He had attended a community optometrist 3 days previously, when his vision was $6 / 5$ in his left eye. At presentation, corrected Snellen vision was $6 / 12$ in the right eye and 6/15 in the left. An acute vitelliform-like maculopathy was present in the left eye (Figures 1a and b), and the right macula was normal. This child initially was commenced on treatment against toxoplasma, with oral steroid cover (20 mg prednisolone/ day). Investigations for infective, inflammatory, and paraneoplastic causes all proved negative. Three days later, the vitelliform-like changes resolved to leave RPE changes at the left macula (Figure 1c). The family mentioned that the child had been given a laser 'toy' pointer, purchased via the internet, and had been playing with this on Christmas Day. The child denied looking directly into the laser beam. Examination of the 'toy' laser pointers bought by the family revealed three separate laser devices made in China, blue $(405 \mathrm{~nm})$, green $(532 \mathrm{~nm})$, and red $(650 \mathrm{~nm})$ with outputs of $57 \mathrm{~mW}$ (blue laser), $42 \mathrm{~mW}$ (green laser) and $72 \mathrm{~mW}$ (red laser) respectively (Figures 2a and b). The British Standard states
${ }^{1}$ Department of Ophthalmology, Royal Hallamshire Hospital, Sheffield, South Yorkshire, UK

${ }^{2}$ Department of Ophthalmology, Sheffield Children's Hospital, Sheffield, South Yorkshire, UK

${ }^{3}$ Department of Ophthalmology, Royal Bolton Hospital, Bolton, Lancashire, UK

Correspondence: FM Quhill, Department of Ophthalmology, Royal Hallamshire Hospital, Glossop Road, Sheffield, South Yorkshire

S10 2JF, UK.

Tel: +44 (0)114 2713281 ;

Fax: +44 (0)114 2713682 .

E-mail: fahd.quhill@

sth.nhs.uk

Received: 12 December 2013 Accepted: 13 December 2013 Published online: 17 January 2014 


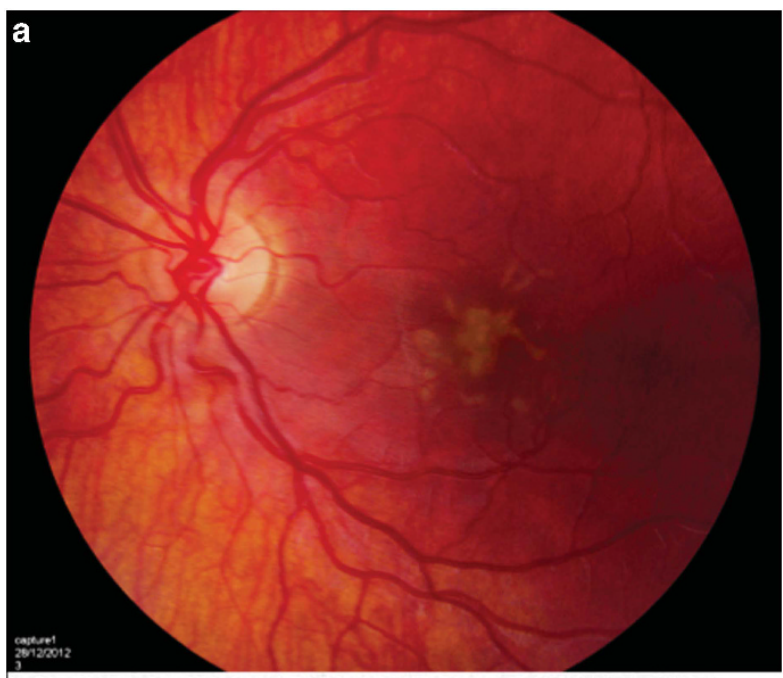

b
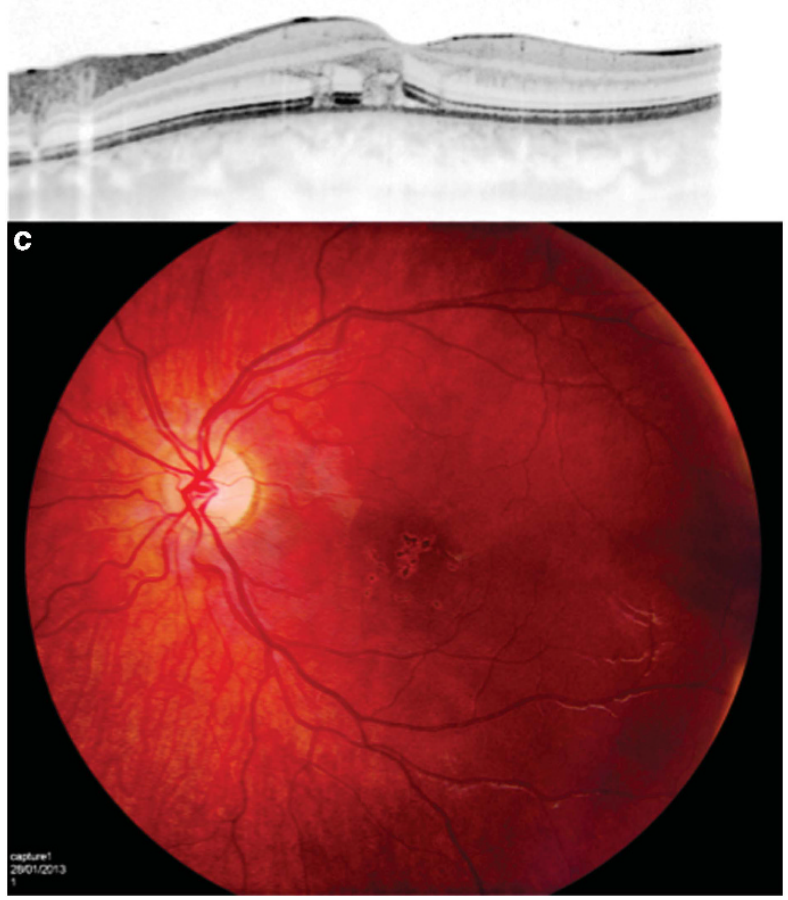

Figure 1 (a) Colour fundus photograph of left eye showing acute phase vitelliform-like maculopathy. (b) Spectral domain OCT image showing outer retinal layer disruption. (c) Retinal pigment epithelial changes at the left fovea 4 weeks post injury.

Class 3R lasers should be $<5 \mathrm{~mW}$. At most recent examination, 9 months post presentation, the child's best corrected visual acuity was 6/9.5 and the OCT imaging reveals persistent outer retinal layer disruption at the fovea.

\section{Case 2}

An 11-year-old boy was referred by his community optometrist with recent onset bilateral decreased vision
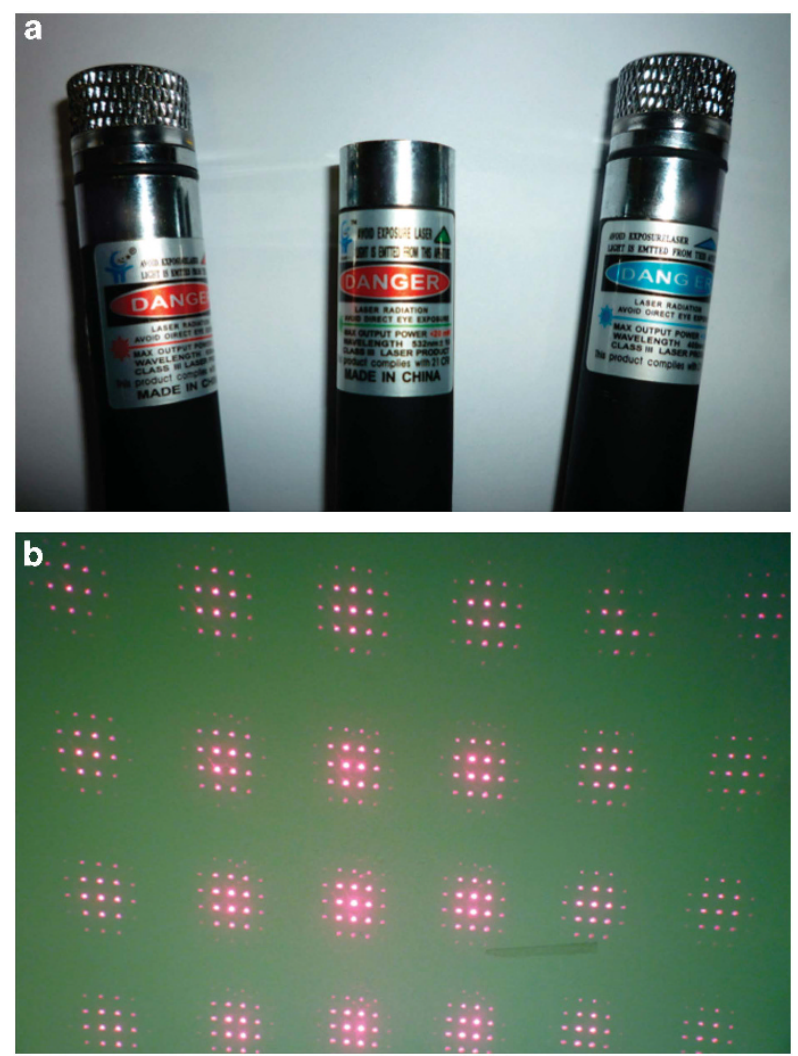

Figure 2 (a) Laser toys purchased via the internet, with label showing class III laser output. (b) Example of a pattern projected by the laser toys.

(best-corrected Snellen acuity of $6 / 7.5$ both eyes at baseline) with bilateral 'yellow' macular lesions. Retinal photographs taken by the optometrist revealed a bilateral vitelliform-like maculopathy, which had resolved to leave sub-foveal RPE changes when he was seen in the paediatric ophthalmology clinic 8 weeks later (Figures $3 a$ and $b$ ). At this point his recorded acuities had deteriorated to $6 / 12$ in the right eye and 6/15 in the left eye. This child admitted that a friend aimed a laser 'toy' into both his eyes prior to him developing decreased visual acuity. We were not able to examine the laser device responsible for injury in this case.

\section{Case 3}

A 15-year-old girl presented with a $24 \mathrm{~h}$ history of blurred vision after shining a laser pointer pen into both eyes for $30 \mathrm{~s}$ the previous day. The visual acuity was $6 / 7.5$ in the right eye and 6/6 in the left, although the patient described scotomas in both eyes. Examination revealed a bilateral vitelliform-like maculopathy. This young person has, so far, failed to attend for follow-up after this initial consultation. 

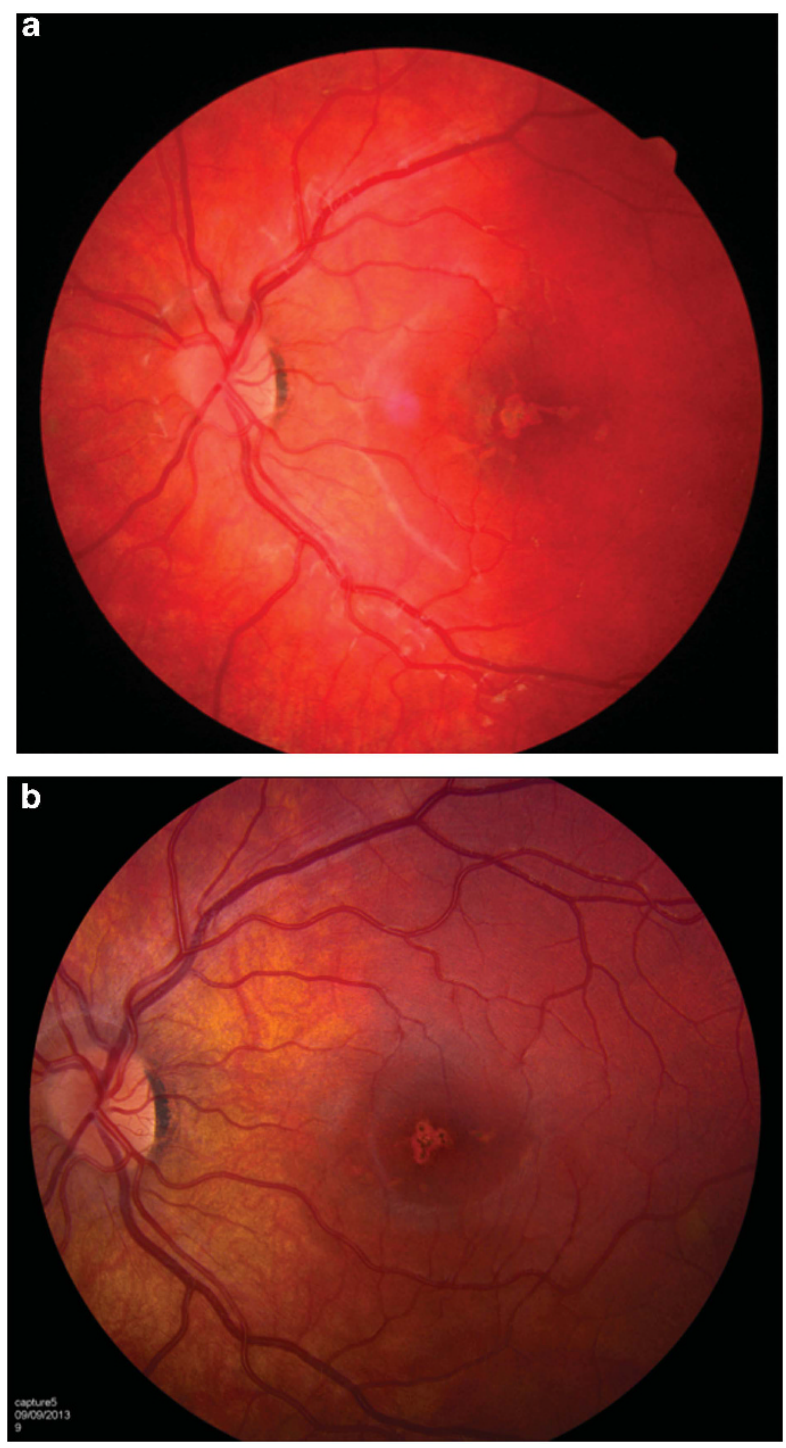

Figure 3 (a) Colour fundus photograph of the left posterior pole, taken by the optometrist, showing an acute vitelliform-like maculopathy. (b) Colour fundus photograph of the left posterior pole showing sub-foveal RPE changes 8 weeks post injury.

\section{Case 4}

An 8-year-old boy attended the emergency department following a minor injury. It was noted that his right visual acuity was reduced and a referral to the paediatric ophthalmology service was made. The child was seen the following day. His best-corrected visual acuity was 6/12 in the right eye and 6/6 in the left. There was no history of amblyopia or significant refractive error. Examination revealed retinal pigment epithelial changes at the right fovea, consistent with laser burns. The child admitted to playing with a laser pointer a few months previously, but denied pointing it directly at his eye. It has not been possible to examine the laser that has caused this injury.

\section{Case 5}

A 13-year-old boy presented with a 2-month history of decreased vision in his right eye. On direct questioning, he admitted shining a laser pointer into this eye before noticing a visual decline. On examination, the best corrected vision in his right eye was 6/36 and 6/6 in the left. Examination revealed a fibrosed choroidal neovascular membrane at the right fovea and a normal left eye.

\section{Discussion}

Laser technology is evolving and laser products are becoming cheaper. So called laser 'toys' can be readily purchased online. It may be difficult to discern if such imported laser toys meet relevant safety standards. Our five children developed maculopathy following exposure to these laser devices, three with a vitelliform-like maculopathy in the acute phase. Similar macular disturbance has been reported following exposure to laser pointers in children. ${ }^{2-4}$ Furthermore similar changes occurred wherein a patient with an ocular melanoma was exposed to a Class 3A green laser pointer prior to enucleation. ${ }^{5}$ The retinal damage reported following such injuries is variable. ${ }^{4-6}$ This is due to variety of laser powers and wavelengths as well as ocular factors such as fundal pigmentation, blink responses, pupil size, and proximity of the laser burn to the fovea. ${ }^{5}$ Assessment of alleged laser eye injury requires accurate history and examination. ${ }^{6}$ Treatment for such laser retinal injuries is uncertain. Oral corticosteroids are sometimes administered. ${ }^{7}$

The present case series highlights the ocular hazards posed by some laser devices, marketed as 'toys'. With the expansion of online consumer purchasing the regulation and classification of such laser devices is critical. We are also aware of other children in the UK with retinal injury from imported laser pointers purchased in Asia. Such matters have recently been reported from the Kingdom of Saudi Arabia. ${ }^{8}$ Furthermore, one of us (SPK) readily purchased a 1.6 Watt hand-held blue laser pointer from a street vendor in China, which would be classified as Class 4 in UK. We wish to raise awareness of this matter as our experience is that children are often reluctant to admit to such mechanisms of injury. Furthermore, consumers and parents need to be alerted to the potential danger such so-called laser 'toys' pose to vision. We suggest that children should not be given laser pointers as toys. 
What was known before

- There are isolated case reports regarding laser pointer injuries in childhood.

What this study adds

- This is the first case series of paediatric laser 'toy' injuries. We highlight a possible public safety issue regarding socalled laser 'toys'. The output of laser 'toys' may far exceed that accepted for a British Standard Class 2 laser.

\section{Conflict of interest}

The authors declare no conflict of interest.

\section{Acknowledgements}

We thank Steven Carley of the Medical Physics Dept who undertook the tests in Sheffield and to Dr Colin Swift, Medical Physics and Engineering Department, The Christie NHS Foundation Trust, Manchester. We also thank Dr John O'Hagan from the Laser and Optical Radiation Dosimetry Group, Public Health England. We would also like to thank Kim Foster, of the Photography Department in Sheffield, for help in preparation of images.

\section{References}

1 Food and Drug Administration, http:/ /www.fda.gov/ MedicalDevices/Safety/AlertsandNotices/ucm237129.htm, 2010.

2 Dirani A, Chelala E, Fadlallah A, Antonios R, Cherfan G. Bilateral macular injury from a green laser pointer. Clin Ophthalmol 2013; 7: 2127-2130.

3 Fujinami K, Yokoi T, Hiraoka M, Nishina S, Azuma N. Choroidal neovascularization in a child following laser pointerinduced macular injury. Japan J Ophthalmol 2010; 54(6): 631-633.

4 Turkana K, Bryan JS, Gordon AJ, Reddy R, Kwong HM, Sell CH. Laser pointer induced macular damage: case report and mini review. Int Ophthalmol 2012; 32(3): 293-297.

5 Robertson DM, McLaren JW, Salomao DR, Link TP. Retinopathy from a green laser pointer: a clinicopathologic study. Arch Ophthalmol 2005; 123(5): 629-633.

6 Mainster MA, Stuck BE, Brown J. Assessment of alleged retinal laser injuries. Arch Ophthalmol 2004; 122: 1210-1217.

7 Barkana Y, Belkin M. Laser eye injuries. Surv Ophthalmol 2000; 44(6): 459-478.

8 Alsulaiman SM, Alrushood AA, Almasaud J, Alzaaidi S, Alzahrani Y, Arevalo JF et al. King Khaled Eye Specialist Hospital Collaborative Retina Study Group. High-power handheld blue laser-induced maculopathy: the results of the King Khaled Eye Specialist Hospital Collaborative Retina Study Group. Ophthalmology 2013; e-pub ahead of print 1 November 2013; doi:10.1016/j.ophtha. 2013.09.006. 